Bevista Eletrônica

REF - ISSN 1808-0804 Vol. VI (3), 59 - 69, 2009

\title{
CARACTERIZAÇÃO FÍSICO-QUÍMICA DO PÓ DAS FOLHAS DE EUGENIA DYSENTERICA DC. (MYRTACEAE)
}

Physico-chemical characterization of Eugenia dysenterica DC. (MYRTACEAE) leaves powder

\section{Renê O. do Couto; ${ }^{1}$ Artur B. Valgas; Maria Tereza F. Bara ${ }^{1}$; José Realino de Paula ${ }^{1}$.}

${ }^{1}$ Laboratório de Pesquisa em Produtos Naturais, FF/ UFG, C.P. 131, Goiânia-GO, 74001-970, Brasil.

\section{Recebido em 09/01/2009 - Aceito em 08/07/2009}

RESUMO: O objetivo desse trabalho foi a caracterização físico-química do pó das folhas de Eugenia dysenterica DC., espécie endêmica no Cerrado brasileiro cujas folhas e frutos são utilizados na medicina popular regional. A droga vegetal foi submetida a ensaios físicos (índice de intumescência, substâncias extraíveis por álcool e determinação de umidade) e químicos (prospecção fitoquímica, teor de cinzas totais, teor de cinzas insolúveis em ácido, teor de polifenóis totais, teor de taninos totais e teor de flavonóides totais). Foi observada quantidade apreciável de compostos fenólicos, flavonóides e taninos, além da presença de saponinas e terpenos, sugerindo um importante potencial fitoterapêutico a ser investigado. Como não foram encontrados na literatura especificações para todos os ensaios realizados, os dados obtidos nesse trabalho subsidiam estudos futuros e contribuem para a obtenção de informações relevantes acerca da padronização e controle de qualidade da matéria-prima dessa espécie, ressaltando sua importância e a necessidade da conservação do Bioma Cerrado.

PALAVRAS-CHAVE: controle de qualidade, compostos fenólicos, planta medicinal.

ABSTRACT: The aim of this work was the physico-chemical characterization of Eugenia dysenterica DC. leaves powder, a Cerrado (Brazilian savanna) endemic specie that its fruits and leaves are used in the regional folk medicine. The herbal drug was analyzed by several physical (swelling index, extractive substances by alcohol and moisture content) and chemical techniques (phytochemical screening, total ashes content, acid insoluble ashes content, total polyphenol contents, total tannin contents and total flavonoid contents). It was observed highly contents of phenolic compounds, flavonoids and tannins, beyond to the presence of saponins and terpenes, suggesting an important phytotherapeutical potential to be investigated. As it wasn't found in the literature specifications for all achieved assays, the found data of this work provides future studies and contribute for the 
Bara, M. T. F. et al./Revista Eletrônica de Farmácia Vol 6(3), 59-69, 2009.

obtainment of relevant information about this specie raw material standardization and quality control, emphasizing its importance and the necessity of the Cerrado Biome conservation.

KEY-WORDS: quality control, phenolic compounds, medicinal plant. 
Bara, M. T. F. et al./Revista Eletrônica de Farmácia Vol 6(3), 59-69, 2009.

\section{INTRODUÇÃO}

O uso de plantas medicinais no Brasil vem se consolidando nos últimos tempos, em especial com a promulgação da Política Nacional de Plantas Medicinais e Fitoterápicos (BRASIL, 2006). Dados da Organização Mundial da Saúde (OMS) mostram que metade dos habitantes da Terra, especialmente em países pobres e em desenvolvimento, faz uso de plantas medicinais na busca do alívio de sintomatologia dolorosa ou desagradável, e que desse total pelo menos $30 \%$ as utilizam por indicação médica (ESTRELA, 1995).

Atualmente, as plantas medicinais não são apenas vistas como recursos terapêuticos, mas também como fontes de recursos econômicos, o que torna cada vez mais importante o estabelecimento de critérios para o desenvolvimento de fitoterápicos confiáveis (GUERRA \& NODARI, 2000).

O Cerrado, dentro da biodiversidade brasileira, é fonte de muitas espécies vegetais que desempenham importante papel na medicina popular (RODRIGUES \& CARVALHO, 2001). Neste cenário destacam-se espécies da família Myrtaceae, uma das mais importantes famílias da flora brasileira, com 23 gêneros e aproximadamente 1000 espécies (SOUZA \& LORENZI, 2008). Representante dessa família, Eugenia dysenterica DC. (cagaita ou cagaiteira) é uma espécie frutífera nativa do Cerrado, aproveitada pela população local tanto para fins alimentares, quanto medicinais (ALMEIDA et al., 1998).

O uso alimentar da cagaita é bastante difundido, sendo os frutos consumidos ao natural, devendo apenas ser tomadas algumas precauções em relação à quantidade ingerida, por que pode tornar-se laxante, principalmente quando fermentados ao sol (ALMEIDA et al., 1998).

Quanto ao uso medicinal, além do efeito purgativo dos frutos, a garrafada das folhas apresenta ação antidiarréica e também utilizada no tratamento de problemas cardíacos (BRANDÃO, 1991), diabetes e icterícia (SILVA, 1999). Além disso, Costa et al. (2000) verificaram resultados positivos acerca da atividade antifúngica in vitro do óleo essencial de folhas de cagaiteira sobre Cryptococcus neoformans.

Dentre a grande diversidade de plantas medicinais do Cerrado, a cagaita foi selecionada para este trabalho, em virtude de sua pluralidade de usos e da escassez de trabalhos científicos a seu respeito. Tendo em vista a necessidade de uma padronização farmacognóstica da planta, realizou-se este trabalho, cujo objetivo foi obter parâmetros preliminares de controle de qualidade da droga vegetal oriunda das folhas de $E$. dysenterica.

\section{METODOLOGIA}

\section{Coleta e preparo do material botânico}

Uma amostra de folhas foi coletada, no turno matutino durante o período de pré-antese de um espécime adulto (Fig. 1) localizado na zona rural do município de Nova América-GO, em maio de 2007. A árvore foi marcada com placa de identificação e as coordenadas geográficas definidas através de GPS manual (W 490 59' 00,5"/S 150 00' 29,5" / 674m).

Depois de identificada pelo Prof. Dr. José Realino de Paula, uma exsicata foi preparada 
Bara, M. T. F. et al./Revista Eletrônica de Farmácia Vol 6(3), 59-69, 2009.

para depósito no Herbário da UFG. No Laboratório de Pesquisa em Produtos Naturais (LPPN) da Faculdade de Farmácia da Universidade Federal de Goiás, a amostra foi dessecada à temperatura ambiente, triturada em moinho de facas e acondicionada ao abrigo de luz e umidade.

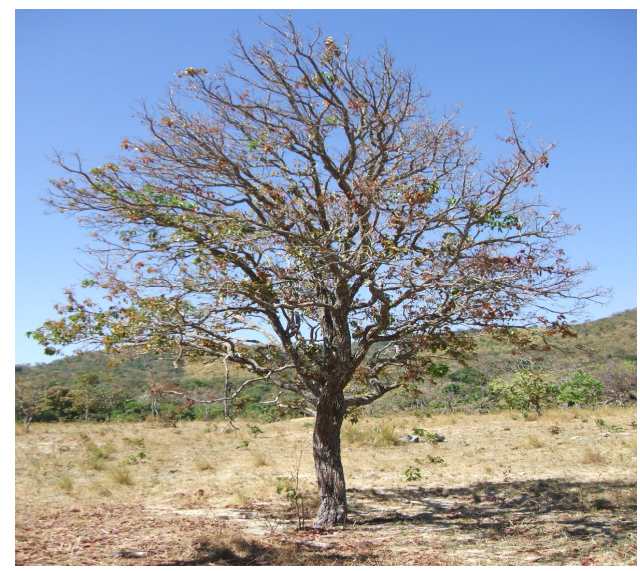

Figura 1: Aspecto geral de E. dysenterica DC. - R. O. do Couto, agosto de 2008.

\section{Prospecção fitoquímica}

Os testes qualitativos para a identificação das principais classes de metabólitos secundários foram baseados nas metodologias descritas por Costa (2001).

Para identificar o grupo de heterosídeos antraquinônicos foi usada a reação de Bornträger; no grupo de heterosídeos esteróides/triterpenóides foram usadas às reações de Liebermann-Burchard, KellerKilianie, Pesez e de Kedde; no grupo de heterosídeos flavonóides foram usadas às reações de Shinoda e Oxalo-Bórica, além das reações com Hidróxidos Alcalinos, $\mathrm{AlCl}_{3}$ e $\mathrm{FeCl}_{3}$; no grupo de heterosídeos saponínicos foi determinado o índice de espuma; no grupo de taninos foram usadas às reações com gelatina, alcalóides (sulfato de quinino a 1\%), sais metálicos (acetato de cobre a $4 \%$ e cloreto férrico a $2 \%$ ) e hidróxido de sódio a $20 \%$; no grupo de alcalóides foram usados os reativos de Mayer, Dragendorff, Bouchardart, Bertrand, Hager e reação com Ácido Tânico. Finalmente, no grupo das cumarinas foi usado teste da fluorescência, sob luz UV, após adição de $\mathrm{NaOH}$ $1 \mathrm{~N}$.

\section{Caracterização Físico-química da droga vegetal}

Procedeu-se a realização da determinação do teor de cinzas totais e insolúveis em ácido (FARMACOPÉIA BRASILEIRA IV, 2000), determinação do Índice de Intumescência (FARMACOPÉIA BRASILEIRA IV, 2000), determinação do teor de substâncias extraíveis por álcool (FARMACOPÉIA BRASILEIRA IV, 1988), determinação do teor de umidade (FARMACOPÉIA BRASILEIRA IV, 2000) e determinação dos teores de polifenóis, taninos e flavonóides totais.

As determinações de polifenóis e taninos totais seguiram metodologia adaptada de Hagerman \& Butler (MOLE \& WATERMAN, 1987 a e b), enquanto os flavonóides totais foram determinados usando o método 
Bara, M. T. F. et al./Revista Eletrônica de Farmácia Vol 6(3), 59-69, 2009.

espectrofotométrico com $\mathrm{AlCl}_{3}$ (KUMAZAWA; HAMASAKA; NAKAYAMA, 2004).

\section{RESULTADOS E DISCUSSÃO \\ Prospecção fitoquímica}

Os dados obtidos (Quadro 1) indicam a presença de grupos de substâncias normalmente associados a diferentes atividades biológicas e que poderão justificar o uso medicinal da espécie. Além disso, estes concordam com os observados em outras espécies representantes da família Myrtaceae, uma vez que em estudos anteriores realizados em nosso laboratório, Paula et al. (2005) e Fiuza et al. (2008) observaram a presença dessas mesmas classes de metabólitos secundários nas folhas de Pimenta pseudocaryophyllus (GOMES) L. R. LANDRUM. e Eugenia uniflora L., respectivamente.

\begin{tabular}{cc}
\hline Classe de Metabólito Secundário & Resultados \\
\hline Heterosídeos antraquinônicos & - \\
Heterosídeos flavonóides & + \\
Alcalóides & - \\
Esteróides / terpenóides & $+/+$ \\
Taninos & - \\
Heterosídeos saponínicos & Índice de espuma $<100$ \\
Cumarinas
\end{tabular}

Quadro 1: Resultados obtidos na prospecção fitoquímica do pó das folhas de $E$. dysenterica.

Espécies da família Myrtaceae, por possuírem atividade consagrada na cultura popular ou por terem sido estudadas em pesquisas científicas, fazem parte de Monografias da Farmacopéia Brasileira IV e/ou da World Health Organization (WHO), dentre elas: Eucalyptus globulus Labill., o eucalipto, cujas folhas ricas em óleo essencial (70\% cineol) são utilizadas como expectorantes para o tratamento de afecções do trato respiratório (FARMACOPÉIA BRASILEIRA IV, 1996; WHO, 2002); Syzygium aromaticum (L.) Merr. \& Perry, o cravo-da-índia, cujos botões florais, ricos em eugenol são utilizados em aplicações externas ou locais para o tratamento da dor de dente e infecções na pele, na forma de pastilhas para o tratamento de dor de garganta e tosses associadas ao resfriado comum (FARMACOPÉIA BRASILEIRA IV, 2002; WHO, 2002); Psidium guajava L., a goiabeira, cujas folhas jovens, ricas em taninos e óleo essencial são utilizadas no tratamento das diarréias infantis (FARMACOPÉIA BRASILEIRA IV, 2002; LORENZI \& MATOS, 2002); Eugenia uniflora L., a pitangueira, cujas folhas, ricas em taninos e óleo essencial são utilizadas na medicina 
Bara, M. T. F. et al./Revista Eletrônica de Farmácia Vol 6(3), 59-69, 2009.

caseira como febrífuga, antireumática e flavonóides possam apresentar efeito antidisentérica (FARMACOPÉIA BRASILEIRA IV, 2003; LORENZI \& MATOS, 2002); Melaleuca alternifolia (Maiden \& Betche) Cheel, óleo de melaleuca, utilizado em aplicações tópicas para o tratamento sintomático de desordens comuns da pele como, acne, furúnculos e micoses (WHO, 2002).

Plantas ricas em taninos são empregadas na medicina tradicional no tratamento de várias moléstias, tais como diarréia, hipertensão arterial, reumatismo, hemorragias, feridas, queimaduras, problemas estomacais (azia, náusea, gastrite e úlcera gástrica), problemas renais e do sistema urinário e processos inflamatórios em geral (HASLAM, 1996; DE BRUYNE et al., 1999; DUFRENSE \& FARNWORTH, 2001).

O emprego medicinal de plantas contendo flavonóides é vasto e, em muitos casos, ainda empírico. Embora alguns resultados tenham mostrado que alguns mutagênico, em geral, são considerados como benéficos. Outras pesquisas sugerem que alguns flavonóides são responsáveis por ação antitumoral considerável, podendo ainda agir como antivirais, anti-hemorrágicos, hormonais, antinflamatórios, antimicrobianos e antioxidantes (ZUANAZZI \& MONTANHA, 2005).

\section{Caracterização Físico-química da droga vegetal}

Não foram encontrados na literatura limites específicos para a espécie $E$. dysenterica relacionados a todas as análises realizadas neste trabalho (Tabela 1). Porém, estes ensaios fazem parte das diretrizes da WHO e da Agência Nacional de Vigilância Sanitária (ANVISA) para o controle de qualidade de plantas medicinais e são essenciais para garantir a autenticidade, a estabilidade e a segurança tanto de plantas medicinais como de seus preparados.

Tabela 1: Propriedades físico-químicas do pó das folhas de E. dysenterica.

Ensaio

Resultado*

Cinzas totais

Cinzas insolúveis em

ácido

Substâncias extraíveis

por álcool

Umidade
$2,948 \pm 0,073 \%$

$0,294 \pm 0,002 \%$

$34,975 \pm 1,772 \%$

$8,154 \pm 0,132 \%$

\section{Especificações da}

Literatura

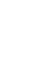


Bara, M. T. F. et al./Revista Eletrônica de Farmácia Vol 6(3), 59-69, 2009.

\section{Índice de inumescência $\quad 2,73 \pm 0,23$}

Polifenóis totais

Taninos totais

Flavonóides totais
$177,32 \pm 5,35 \mu \mathrm{g} / \mathrm{mg}$

$95,22 \pm 1,84 \mu \mathrm{g} / \mathrm{mg}$

* Resultados expressos pela média \pm desvio padrão de três determinações.

Dessa forma, o teor de extrativos pode fornecer informações muito relevantes sobre o rendimento dos mais variados processos extrativos que podem ser empregados na transformação tecnológica da droga vegetal. Outrossim, o índice de intumescência é importante para prever o volume de solvente extra que deve ser adicionado durante a produção desses extratos.

A presença de quantidade excessiva de água em drogas vegetais propicia 0 desenvolvimento de microorganismos, insetos, a hidrólise e a atividade enzimática com conseqüente deterioração dos constituintes da droga. O baixo conteúdo de umidade indica que houve eficiência durante $\mathrm{o}$ processo de secagem e que o material é estável (OLIVEIRA; AKISUE; AKISUE, 1991).

A determinação do teor de cinzas totais foi utilizada para a determinação de substâncias inorgânicas não voláteis que poderiam estar presentes como constituintes ou contaminantes na droga vegetal. Já a determinação de cinzas insolúveis em ácido destinou-se à quantificação de sílica e constituintes silicosos na droga vegetal.
Uma vez que compostos fenólicos, como taninos e flavonóides podem ser os responsáveis pelas atividades farmacológicas da espécie, é imprescindível a determinação de seus teores na droga vegetal. A verificação do perfil de produção desses metabólitos secundários é importante no que tange os requisitos propostos para a padronização da droga vegetal. É válido salientar o alto teor de taninos e flavonóides observados neste estudo, uma vez que estes totalizaram cerca de 53,7 e $3,45 \%$, respectivamente, dos compostos fenólicos totais encontrados, ratificando os resultados obtidos na prospecção fitoquímica, bem como o potencial terapêutico da espécie. Esses compostos chamam a atenção em razão de suas conhecidas propriedades antioxidantes, manifestadas pela habilidade de seqüestrarem radicais livres ou pela prevenção da oxidação das lipoproteínas de baixa densidade (NEWALL; ANDERSON; PHILIPSON, 2002; MILIAUSKAS; VENSKUTONIS; VAN BEEK, 2004; ALBU et al., 2004).

A metodologia empregada para a determinação dos teores de polifenóis e taninos totais é baseada na capacidade dos compostos fenólicos reagirem com sais metálicos, como 
Bara, M. T. F. et al./Revista Eletrônica de Farmácia Vol 6(3), 59-69, 2009.

$\mathrm{FeCl}_{3}$, em meio alcalino, formando soluções de coloração enegrecida, além da capacidade de os taninos precipitarem compostos de origem protéica, pela complexação das hidroxilas fenólicas com os grupamentos amina dos aminoácidos.

No caso dos flavonóides totais, o princípio do método é o de que o $\mathrm{AlCl}_{3}$ forma complexos ácidos estáveis com o grupamento cetona de C-4 e as hidroxilas das posições C-3 e/ou C-5 das flavonas (crisina, apeginina, luteolina) e flavonóides (rutina, morina,

\section{CONCLUSÕES}

Os resultados obtidos fornecem informações preliminares importantes quanto ao perfil de produção de metabólitos secundários pela espécie estudada, principalmente compostos fenólicos, como taninos e flavonóides. Estes dados são quercetina, miricetina, campferol, quercitrina e galangina). Além disso, $\mathrm{AlCl}_{3}$ forma complexos ácidos lábeis com os grupamentos ortodihidroxil dos anéis $A$ e $B$ dos flavonóides.

As análises das regressões lineares das curvas padrão de ácido tânico e quercetina expressam a confiabilidade dos resultados obtidos nas determinações desses metabólitos, uma vez que as equações das retas foram lineares $\left(R^{2}>0,99\right)$ e os coeficientes de variação dos doseamentos foram menores que 5\% (BRASIL, 2002).

importantes como conhecimentos básicos e podem ser aplicados na padronização e controle de qualidade da matérias-primas vegetais obtidas apartir das folhas de E. dysenterica. Isso ressalta a importância da espécie e da conservação do Bioma Cerrado, o mais ameaçado no país devido aos avanços da fronteira agrícola. 
Bara, M. T. F. et al./Revista Eletrônica de Farmácia Vol 6(3), 59-69, 2009.

\section{REFERÊNCIAS BIBLIOGRÁFICAS}

ALAMEIDA, S. P.; PROENÇA, C. E. B.; SANO, S. M.; RIBEIRO, J. F. Cerrado: espécies vegetais úteis. Planaltina: Embrapa CPAC, DF. 464p., 1998.

ALBU, S.; JOYCE, E.; PANIWNYK, L.; LORIMER, J.P.; MASON, T.J. Potential for the use of ultrasound in the extraction of antioxidants from Rosmarinus officinalis for the food and pharmaceutical industry. Ultrasonic Sonochemistry, v. 11, p. 261-266, 2004.

BRANDÃO, M. Plantas medicamentosas do cerrado mineiro. Informe Agropecuário. Belo Horizonte. v. 15. n. 168. p. 15-20, 1991.

BRASIL. Agência Nacional de Vigilância Sanitária. Guia para validação de métodos analíticos. DOU 20/03/2002. Resolução RE no 475, de 19 de março de 2002.

COSTA, A. F. Farmacognosia. 3. ed. v. 3. Lisboa: Fundação Calouste Gulbenkian, 2001.

COSTA, T. R.; FERNANDES, O. F. L.; SANTOS, S. C.; OliVEIRA, C. M. A.; LiÃO, L. M.; FERRI, P. H.; PAULA, J. R.; FERREIRA, H. D.; SALES, B. H. N.;SILVA, M. R. R. Antifungal activity of volatile constituents of Eugenia dysenterica leaf oil. Journal of Ethnopharmacology, v. 72, p. 111-117, 2000.

DE BRUYNE, T.; PIETERS, L.; DEELSTRA, H. ; VLIETINCK, A.J. Condensed vegetable tannins: biodiversity in structure and biological activities. Biochemistry and Systematic Ecology, v. 27, p. 445-459, 1999.

DUFRENSE, C.J. \& FARNWORTH, E.R. A review of latest research findings on health promotion properties of tea. Journal of Nutritional Biochemistry, v. 12, p. 404-421, 2001.

ESTRELA, E. Tratado de Cooperaçion Amazonica - Secretaria Protempore, Plantas medicinales Amazônicas: Realidad y Perspectivas, Lima: TCA, 1995.

FARMACOPÉIA BRASILEIRA. 4. ed. Parte 1. São Paulo: Atheneu Editora LTDA, 1988.

FARMACOPÉIA BRASILEIRA. 4. ed. Parte 2. Fascículo I. São Paulo: Atheneu Editora LTDA, 1996.

FARMACOPÉIA BRASILEIRA. 4. ed. Fascículo II. São Paulo: Atheneu Editora LTDA, 2000.

FARMACOPÉIA BRASILEIRA. 4. ed. Fascículo II. São Paulo: Atheneu Editora LTDA, 2002. 
Bara, M. T. F. et al./Revista Eletrônica de Farmácia Vol 6(3), 59-69, 2009.

FARMACOPÉIA BRASILEIRA. 4. ed. Parte 2. Fascículo V. São Paulo: Atheneu Editora LTDA, 2003.

FIUZA, T. S.; REZENDE, M. H.; SABÓIA-MORAIS, S. M. T.; BARA, M. T. F.; TRESVENZOL, L. M. F.; PAULA, J. R. Caracterização Farmacognóstica das folhas de Eugenia uniflora L. (MYRTACEAE). Revista Eletrônica de Farmácia, V. 5, n. 2, p. 21-31, 2008.

GUERRA, M. P. \& NODARI, R. O. Biodiversidade: Aspectos Biológicos, Legais e Éticos. In SIMÕES, C. M. O.; SCHENKel, E. P.; GOSMANN, G.; MELlO, J. C. P.; MENTZ, L. A.; PeTROViCK, P. R. Farmacognosia: da planta ao medicamento. 3. ed. Porto Alegre: RS. Editora da UFSC, 2000.

HASLAM, E. Natural polyphenols (vegetable tannins) as drugs and medicine: possible modes of action. Journal of Natural Products, v.59, p. 205-215, 1996.

KUMAZAWA, S.; HAMASAKA, T.; NAKAYAMA, T. Antioxidant activity of propolis of various geographic origins. Food Chem. v. 84, p. 329-339, 2004.

LORENZI, H. \& MATOS, F. J. A. Plantas medicinais no Brasil: nativas e exóticas. Nova Odessa: Instituto Plantarum, 2002.

MILIAUSKAS, G.; VENSKUTONIS, P.R.; VAN BEEK, T.A., Screening of radical scavenging activity of some medicinal and aromatic plant extracts, Food Chemistry, v. 85, p. 231-236, 2004.

MOLE, S. \& WATERMAN, P. G. A critical analysis of techniques for measuring tannins in ecological studies I. Techniques for chemically defining tannins. Oecologia, Berlin, v.72, p.137 - 147, 1987a.

A critical analysis of techniques for measuring tannins in ecological studies II. Techniques for biochemically defining tannins. Oecologia, Berlin, v.72, p.148 - 156, 1987b.

NEWALL, C.A., ANDERSON, L.A., PHILIPSON, J.D., Plantas Medicinais - guia para profissionais de saúde, São Paulo: Ed. Premier, 2002.

OliVeIRA, F.; AKISUE, G.; AKISUE, M. K. Análise de Drogas. São Paulo: Editora Livraria Atheneu, 1991.

PAULA, J. A. M.; BARA, M. T. F.; ReZENDE, M. H.; FERREIRA, H. D.; PAULA, J. R. Estudo Farmacognóstico das folhas de Pimenta pseudocaryophyllus (GOMES) L. R. LANDRUM - MYRTACEAE. Revista Eletrônica de Farmácia. Suplemento V. 2, n. 2, p. 153 -156, 2005.

RODRIGUES, V. E. G. \& CARVALHO D. A. Plantas medicinais no domínio dos cerrados. Lavras: UFLA, 2001. 
Bara, M. T. F. et al./Revista Eletrônica de Farmácia Vol 6(3), 59-69, 2009.

SILVA, R. S. M. Caracterização de sub-populações de cagaita (Eugenia dysenterica DC.) da região sudeste do estado de Goiás, Brasil. 1999. 107 p. Dissertação (Mestrado) Universidade Federal de Goiás, Goiânia.

SOUZA, V. C. \& LORENZI, H. Botânica sistemática: guia ilustrado para identificação das famílias de Angiospermas da flora brasileira, baseado em APG II. Nova Odessa: Instituto Plantarum, 2008.

ZUANAZZI, J. A. S. \& MONTANHA, J.A. Flavonóides. In SIMÕES, C. M. O.; SCHENKEL, E. P.; GosmanN, G.; MELLO, J. C. P.; MENTZ, L. A.; PETROVICK, P. R. Farmacognosia: da Planta ao Medicamento. 5. ed. Porto Alegre: RS. Editora da UFSC, 2005.

WHO, World Health Organization, Monographs on selected medicinal plants, v. 2, Geneva, 2002. 